development officer in a university faculty of health. They have brought together writings from a variety of professionals in management, social work, nursing, midwifery, and education.

Two chapters in this book deserve special mention. Kevin Kendrick's contribution explores the concept of care within research practice. He logically and thoughtfully discusses the guiding principles underpinning caring and researching, keeping a careful balance between the reality of practice and the theoretical constructs. Norma Fryer's chapter deals with informed consent and is similarly focused and clearly ordered.

Unfortunately the rest of the book does not reach the same standard. An odd blend of basic information and advanced philosophical ideas makes it difficult to see for whom this volume was written. There is a perplexing lack of logic and cohesion overall and this, coupled as it is with questionable syntax, a certain imbalance in style and content, and numerous typographical and design errors, leaves the reader having to work hard to extract useful information from this collection of writings. The stated aim of the book, to analyse and debate major issues of professional ethics generally, and of research specifically, was appealing. The reality is that the text does not realise this aim.

HAZEL E MCHAFFIE Institute of Medical Ethics, University of Edinburgh

\section{Contemplating Suicide: the Language and Ethics of Self Harm}

\author{
Gavin J Fairbairn, London, \\ Routledge, 1995, 209 pages, $£ 37.50$ \\ hbk, $£ 12.99$ pbk.
}

This book does more than contemplate the subject of suicide. Gavin Fairbairn is a moral philosopher who has worked in the health care field as a psychiatric social worker. He had, therefore, some personal experience of suicide and those who carry it out (he does not like the word "commit") and aims to produce a book which is of some practical help to those involved.

The philosophical focus of the book is on intention. Fairbairn's assertion is that an act of self harm which results in death cannot be called suicide unless it was the specific intention of the subject to bring about his or her own death. Conversely, if the subject has acted with this intention and does not succeed this is also to be termed suicide even though the subject is still alive. In other words, the intention to bring about one's own death is both necessary and sufficient for suicide. This assertion leads the author to reject the current range of terms used to describe acts of self harm, such as "parasuicide", "non-fatal" suicide, and "threatened" suicide, as being illdefined and unhelpful. He offers an alternative vocabulary including "cosmic roulette", to define a situation where the self harmer is in doubt about his intent, and "gesturing at suicide", where the intent is not to die, in order to cover situations which are not suicide in the terms of his definition. This new "taxonomy" is helpful in clarifying what Fairbairn has shown to be a muddle and it also allows him to explore his own definition.

Having dealt with what is not suicide Fairbairn spends the remainder of the book examining what is. He considers the possible contexts which might lead an individual to perform the act, such as a feeling of altruism or duty or a desire for revenge; and he discusses the possibility of intervention in a suicidal act and the implications this has for autonomy.

In an interesting "archaeological" chapter Fairbairn examines wellknown historical acts of suicide from the point of view of his thesis. He does not come to any firm conclusion on whether the death of Socrates (which he compares with the ritual suicide of a Japanese seppuku) was suicide or not and his final comments in this section raise a major point on which the book is not clear. Fairbairn's thesis is that the definition of an act of self harm depends on the intent of the person performing it. His comment on the death of Socrates is that his death was suicide only if he intended to take his life because he wished to be dead. This suggests that the intention to die is necessary but not sufficient. There seems in this case to be a further necessary condition: the wish to die. Are both the intention to commit suicide and the wish to die necessary for his definition? I am not sure.

My only other reservations about the book are minor ones. Firstly, the use of the word suicide as a verb (as in "he suicided") does not seem to have validity as far as the Oxford English Dictionary is concerned and I found it grated in reading the book. Fairbairn explained this usage by saying that he wished to avoid the word "commit" which he felt was loadec by its association with "to commit murder". I think that in the context of his detailed discussion this loading would disappear. Secondly, some of the examples used were so long and involved that the distinctions the author was trying to make were lost in the midst of his flights of imagination. The story of $\mathrm{Mr}$ Pailin, who took his own life in the mistaken belief that his daughter had died in an accident and thus pleased his unfaithful wife who had already planned with her lover to murder him, is a case in point.

This is an interesting book which covers the conceptual ground comprehensively, in an entertaining way and makes a good case for a new terminology for acts of self harm. It should be read by doctors, nurses and social workers who have an involvement with suicide and who are interested in the philosophical issues it raises. Since the author wishes the book to be of practical value to those in the field and does not give much attention to a discussion of the morality of suicide - a point of major interest to philosophy - it may not be so attractive to philosophers.

JANE MACNAUGHTON Department of General Practice, University of Glasgow

\section{Buddhism and Bioethics}

Damien Keown, London and New York, MacMillan and St Martin's Press, 1995, 208 pages, $£ 40$.

Dr Keown has produced a very important book in the fields of crosscultural ethics and Buddhist studies. His goals are stated modestly yet are, in fact, fundamentally ambitious. $\mathrm{He}$ set out to write the first study ever to present a Buddhist overview of bioethics that is simultaneously intelligible and interesting to general readers, to specialists in Buddhist studies, and to medical ethicists.

I think he has succeeded very well. This clearly written, carefully researched, and systematically structured volume will be a necessary work for all subsequent writers and researchers in the field. There is no better source than this book for the nonspecialist who wants an introduction to 